\title{
Study on the determination of the reasonable finished state for cable-stayed bridge with hybrid girder
}

\author{
GUO Junfeng ${ }^{1, a}$, WANG Jinzhi, ${ }^{2, b}$ \\ ${ }^{1}$ Wuhan municipal engineering research and design institute CO.LTD, Wuhan430023, CHINA \\ ${ }^{2}$ Wuhan University of Technology Huaxia College, Wuhan430063, CHINA \\ a429761683@qq.com, binzhiwang2005@163.com
}

Keywords: composite girder cable-stayed bridge; the reasonable finished state; finite element method

\begin{abstract}
In order to obtain the optimal values of cable force, and determine the reasonable finished bridge state for large span Cable-stayed bridge with hybrid girder, the space finite element simulation analysis model of the whole bridge is established, considering the characteristics of its span arrangement and structure, analysis the method and basic principles for determining the reasonable finished bridge state, calculated with the influence matrix method and minimum bending energy method, and the objective function is minimization the maximum displacement of tower and girder. Through calculation, the stress of the main pylon, the main girder and the stay cables in the finished state and the operating state can satisfy the requirements of standard, the reasonable finished state of cable-stayed bridge in accordance with the requirements.
\end{abstract}

\section{Introduction}

The cable-stayed bridge with hybrid girder type can greatly improve concrete beam weights and steel beam spanning capacity, and make full use of two kinds of materials with certain economy. The E-dong Yangtze River Bridge, Jingyue Yangtze River Bridge [1], Guangzhou Dongsha Bridge, Jiujiang Yangtze River Bridge and other cable-stayed bridge with hybrid girders has built in these decades. With the development of bridge engineering, bridge span is more and more big; there will be more and more cable-stayed bridge with hybrid girder.

The cable-stayed bridge is a statically indeterminate structure, cable force value has many group schemes, at the same time, and the cable supporting system is supporting system of the main beam, the different cable force value will enforce different structure force condition of the main tower and the main girder [2, 3]. So that it is important that obtaining a group scheme of cable force value, in which condition, the mechanical performance of the cable-stayed bridge structure under the action of load is the optimal state. The finished state of cable-stayed bridges corresponding to this group scheme of the cable force is the reasonable finished state on an optimal mechanical performance goal. It is important for determining the reasonable finished state of the cable-stayed bridge with hybrid girder to determine the internal force and stress of cable-stayed bridge structure and critical stress state in the process of construction. In this paper, the method to determine the reasonable finished state on the engineering background of a long span cable-stayed bridge with hybrid girder.

\section{Project Profile}

The cable-stayed bridge with hybrid girder is located in Wanzhou City, the span arrangement is $4 \times 57.5+730+4 \times 57.5=1190 \mathrm{~m}$, with the first grade highway road design level and city bridge traffic function, the design speed is $60 \mathrm{~km} / \mathrm{h}$. The bridge vehicle design load is grade - I highway, the design reference period is 100 years. Deck layout is two-way six lanes with each lane $3.5 \mathrm{~m}$ width, $3.0 \mathrm{~m}$ sidewalk width, $0.5 \mathrm{~m}$ bandwidth, $3.5 \mathrm{~m}$ median, anchorage zone of bridge set and a crash barrier. The beam is Q345 steel box girder at the main span, and C55 concrete box girder and the side span; 
the steel-concrete joint part is arranged on the main span $2.5 \mathrm{~m}$ away from the main tower center. The elevation layout and plane layout figure of the cable-stayed bridge are shown in Figure 1.

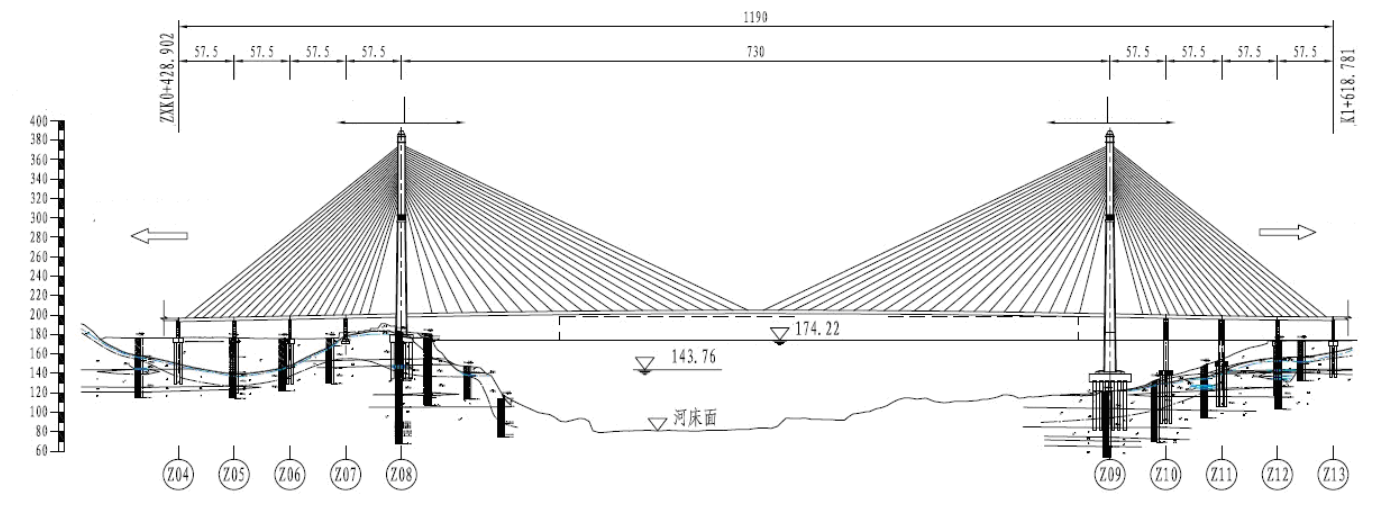

Fig. 1 The elevation layout of the cable-stayed bridge

The cable-stayed bridge with hybrid girder used 9cross continuous semi floating system structure, space close cable arrangement. Vertical bearing installed on the main girder at the position of the pylon and auxiliary pier intersection, while lateral wind resistant support at the intersection of the pylon and the main girder, the seismic block on the auxiliary pier.

The main pylon is the diamond shape pylon with the European architectural style, the upper pylon between the upstream and downstream section of the cable arranged 6 connecting beams, the under pylon pier arranged one crossbeam. North and south main pylon above the under crossbeam remains the same, is different only under pylon structure. The main girder is hybrid girder with steel box girder at the main span and prestressed concrete box girder at the side span; the steel-concrete joint part is arranged on the main span $2.5 \mathrm{~m}$ away from the main pylon center. The steel box girder is streamlined flat steel box girder structure with orthotropic bridge deck, 3.5m height at the center line of the girder, $37.2 \mathrm{~m}$ full width (including wind mouth), $36 \mathrm{~m}$ width deck, $2 \%$ two-way drainage slope. The concrete girder makes use of C55 concrete with $231.80 \mathrm{~m}$ length in total. Longitudinal prestressed steel is $\varphi s 15.2 \mathrm{~mm}$ steel wire, with plastic corrugated pipe hole and group anchor structure. The cable is $\varphi 7 \mathrm{~mm}$ galvanized or zinc aluminum coated steel wire with the fan-shaped missile system. The cables are 172 in number and a total of 7 kinds on number of wire specifications, such as PESC7-121, PESC7-139, PESC7-163, PESC7-199, PESC7-223, PESC7-253, and PESC7-241.

\section{Finite Element Models}

The space finite element model of the bridge is established using the large general software MIDAS civil, as shown in Figure 2, the main girder and main pylon simulated by beam element, the cable simulated by truss element, The space finite element model of the bridge is 800 nodes and 631 element in total, the connection between the cable and the main girder and main pylon simulated by rigid connection, while the connection between the main girder and pier by longitudinal and transverse freedom bearing, the connection between the main girder and main pylon by vertical elastic connection.

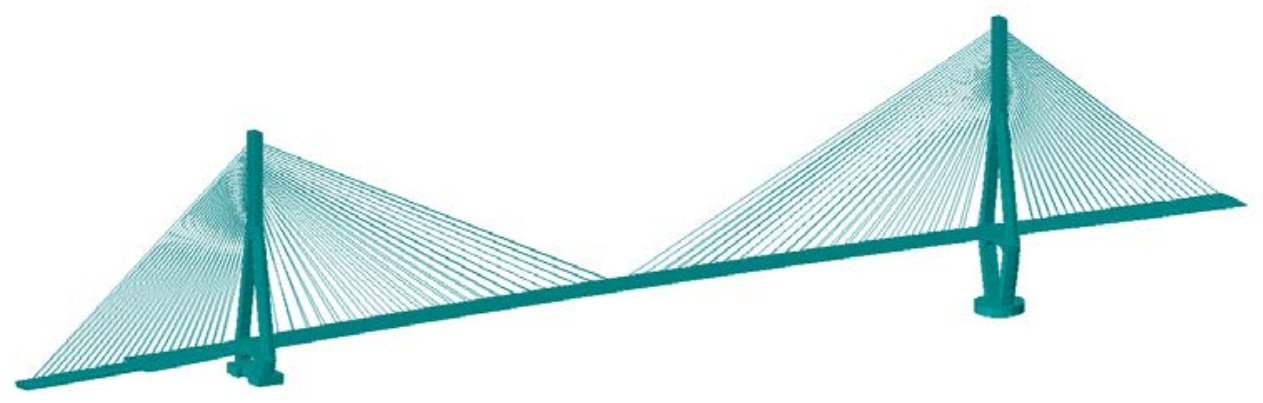

Fig.2 The space finite element model of the bridge 
The concrete box girder, steel box girder, main pylon and stayed cable in the model use different kinds of materials, the materials and materials parameters shown in Table 1 . In the model, for prestressed steel strand, the elastic modulus is $1.95 \times 105 \mathrm{MPa}$, standard strength $1860 \mathrm{MPa}$, tension control stress $1395 \mathrm{MPa}$, for the cable, elastic modulus is $2.05 \times 105 \mathrm{MPa}$, standard strength $1670 \mathrm{MPa}$, control stress 668Mpa, using state safety factor 2.5 .

Table. 1 The materials and materials parameters

\begin{tabular}{|c|c|c|}
\hline Number & member & material \\
\hline 1 & steel box girder & Q345qD \\
\hline 2 & concrete box girder & C55 concrete \\
\hline 3 & main pylon & C50 concrete \\
\hline 4 & cable & $\phi 7 \mathrm{~mm}$ parallel steel wire \\
\hline 5 & prestressed steel strand & $\phi$ s 15.2 steel strand \\
\hline
\end{tabular}

The actions considered in the calculation mainly includes constant action (including weight, saddle weight and secondary constant action), road grade- I, crowd, temperature (including the overall warming, overall cooling, heating temperature gradient of the main girder, cooling temperature gradient of the main girder, cable heating, cable cooling, difference in left and right temperature of the main pylon) and wind (including longitudinal and transverse wind).

\section{The Selection of the Reasonable Finished State Determination Method}

The frequently-used solution methods of the bridge cable force values on the reasonable finished state mainly include zero displacement method, rigid support continuous beam method, influence matrix method, minimum bending energy method and so on.

Zero Displacement Method. The cable-stayed bridge structure support the constant action on finished state, the method making the displacement of cable and main girder adjustment equal to zero through adjusting the cable force, is called the zero displacement method. This method is suitable for the cable-stayed bridge with large stiffness such as the low pylon cable-stayed bridge. The cable is easy to adjust to the target state. But for the Wanzhou Yangtze River Bridge as large span cable-stayed bridge, it is difficult to reach the target state by using this method, while adjusting the cable force is not necessarily though zero displacement method. But the construction method of cantilever installation and cantilever cast-in-place usually adopts in long-span cable-stayed bridge, the displacement of the cantilever construction divide into rigid displacement and bending deformation of the beam, the former can be adjusted in the process of cantilever construction, the latter will affect the force of the beam, the structure stress will not necessarily minimum in zero displacement state, Therefore, the bridge as a long-span cable-stayed bridge is not suitable for zero displacement method.

Rigid Support Continuous Beam Method. Through the adjustment of cable force to make the constant action bending internal force of the cable-stayed bridge structure in the finished state be correspondence with that of rigid support continuous beam in the same conditions, the method of which is called rigid support continuous beam method. That is to say, the supporting force of continuous beam is the vertical component of cable force, however, when the main beam show a longitudinal slope, the cable force present no corresponding relationship with the supporting force of the continuous beam. At the same time, at normal circumstances, the main girder near the main pylon will not layout cable, the cable force value determined according to the rigid support continuous beam method near the main pylon is the largest, the second teams of cable force value will be very small, sometimes negative, is inconsistent with the actual situation, therefore, the cable-stayed bridge with a longitudinal slope is not suitable for rigid support continuous beam method. 
Minimum Bending Energy Method. Making the bending strain energy value of the cable-stayed bridge main pylon or girder as the objective function, the energy principle as the theoretical basis, cable force of cable-stayed bridge got when the bending strain energy of the cable-stayed bridge structure is the minimum value, this method is called the minimum bending energy method. For long-span cable-stayed bridge, the main pylon and the main girder would bear larger axial force and bending moment, it is feasible that making the bending strain energy value of the structure as the objective function to calculate the cable force optimum solution. The specific operation method is: increases the section area value of the main pylon, girder and cable several times, reduce the deadweight, keep the inertia moment, this keep the eliminated energy caused by the axial force and shear force of the main pylon, girder and cable and unchanged bending energy, at this time, the structure only caused by the bending strain energy, the cable tension value while the dead load acting on the structure is the optimal value of the cable force under the minimum bending energy state.

Influence Matrix Method. Influence matrix method is determination method of the bridge cable force values on the reasonable finished state based on the several methods above. This method consider the effect of cable stayed bridge structure stress by the vehicle load, prestress, shrinkage and creep of concrete etc., through different objective function instead of a single parameter as the objective function and through different weighting methods to calculate the optimal value of the cable force. This method consider bridge structure affected by constant action and variable action, at the same time, consider the influence of the bridge mechanical properties by each action with different objective function, is more complete cable force optimization determination theory so far.

The reasonable finished state determination will follow the requirements follow:

- Main pylon bending moment, the bending moment of the main pylon need basic requirements that the bending moment is relatively small on the influence of constant action. If not, the bending moment value of the main pylon will increase on the influence of shrinkage and creep of concrete during the cable-stayed bridges operation period, which is very adverse for the main pylon. At the same time, while the ratio of side span and main span is relatively small for cable-stayed bridge with hybrid girder, on the effect of vehicle load, the main pylon bends toward the span centre direction, the main pylon top appears horizontal displacement toward the span centre direction, thus the main pylon top should set pre offset opposite the span centre direction appropriately on the construction phase.

- Side and auxiliary pier supporting reaction force, the supporting reaction force of side and auxiliary pier need basic requirements that the supporting reaction force is upward on the effect of constant action, while leaving a certain reserve, so as to avoid the supporting reaction force appear negative force which not conform to the actual on operation state.

- Main girder bending moment. The bending moment of the main girder need basic requirements that the bending moment value is in reasonable range, and absolute value of the main girder bending moment remain small as far as possible on the effect of constant action. For cable-stayed bridge, the cable force value change will changed the main girder bending moment greatly. Therefore, the reasonable finished state determination need to focus on the bending moment of the main girder.

- Cable force distribution, the cable force distribution need basic requirements that short cable force is small while long cable force is big and the cable force gradually increased from the pylon to the cross or support side. At the same time, the minimum value of the cable force should greater than the cable force value corresponding sag requirements, the maximum value should less than the maximum cable force value the material allowed.

In view of this kind of long span cable-stayed bridge with hybrid girder, the ratio of side span and main span $(230 / 730=0.315)$ is small, the mid-span is large. A better cable force on finished state cannot get only through one method. The reasonable finished state of the bridge is determined by combining the minimum bending energy method and influence matrix method the two kind methods, viewing the maximum displacement of the main pylon and girder as the goal, taking into account the internal force and stress values of the main pylon, main girder, cable. 


\section{Reasonable Finished State of Wanzhou Yangtze River Bridge}

On the finished operation state, considering constant action, vehicle load and crowd load, the overall warming, temperature gradient and wind load, the stress and deformation of cables, girder and pylon can be obtained. On operation state, the maximum vertical displacement of girder is $743 \mathrm{~mm}$, while the maximum main pylon horizontal displacement is $248 \mathrm{~mm}$, which affect structure integrated linear smooth. The cable stress shown in figure 3, the girder and the main pylon stress envelope diagram shown in figure 4 to 5 can be obtained.

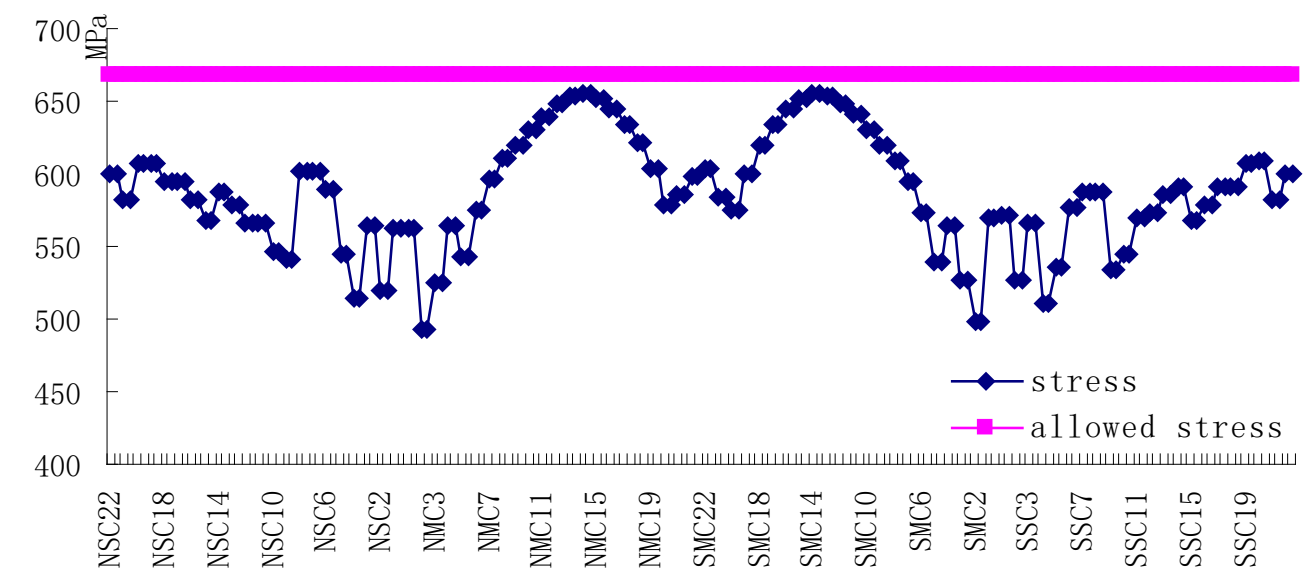

Fig.3 Cables stress on finished operation state
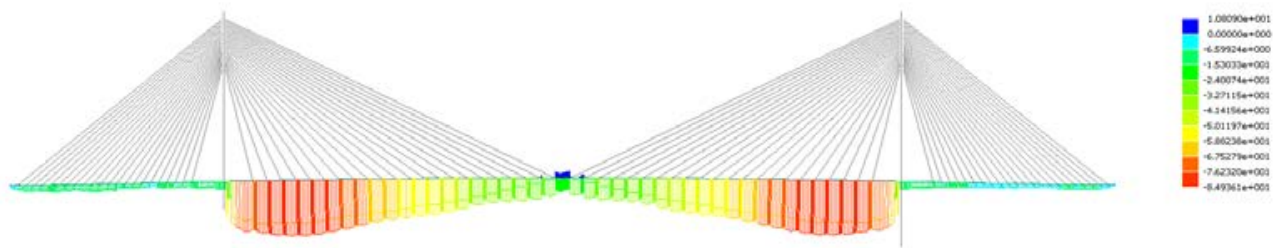

Fig.4 Girder stress on finished operation state

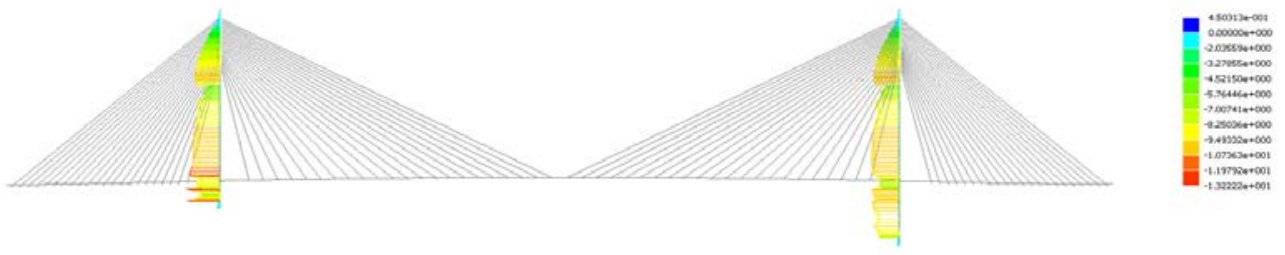

Fig.5 Pylon stress on finished operation state

From above fig. 3 to 5, on the operation state, the maximum cable stress is $661.6 \mathrm{Mpa}$, less than the allowed stress $1670 / 2.5=668 \mathrm{Mpa}$, accord with the requirements. The maximum steel box girder tensile stress is $10.8 \mathrm{Mpa}$, less than the allowed stress $295 \mathrm{Mpa}$, while the maximum pressure stress is 84.9Mpa, less than the allowed stress 295Mpa and the maximum shear stress is $10.7 \mathrm{MPa}$, less than the allowed stress $170 \mathrm{Mpa}$. The maximum concrete box girder tensile stress is $0.9 \mathrm{Mpa}$, less than the allowed stress $1.89 \mathrm{MPa}$, while the maximum pressure stress is $12.2 \mathrm{Mpa}$, less than the allowed stress 24.4Mpa, all of these affect that the girder stress accord with the requirements. The maximum main pylon tensile stress is $0.45 \mathrm{Mpa}$, less than the allowed stress $1.83 \mathrm{MPa}$, while the maximum pressure stress is $13.2 \mathrm{Mpa}$, less than the allowed stress $22.4 \mathrm{Mpa}$, accord with the requirements.

The vertical displacement of the cable stayed bridge under the lane load is calculated shown in figure 6 . 


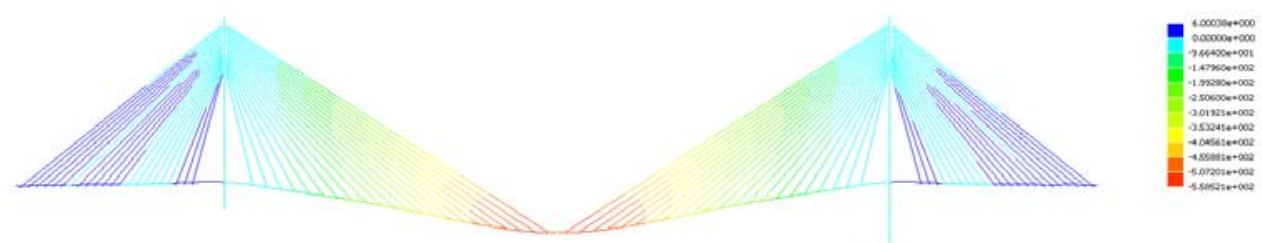

Fig.6 Vertical displacement under lane load

From above fig.6, the vertical displacement under lane load is $559 \mathrm{~mm}$, less than $1 / 400=730 * 1000 / 400=1825 \mathrm{~mm}$, which accord with the requirements of 'Guidelines for design of highway cable—-stayed bridge'.

\section{Summary}

In order to determine the reasonable finished state of cable-stayed bridge with hybrid girder through the whole structure calculation, the whole structure spatial finite element simulation analysis model is established, in which the main girder and pylon simulated by beam element, the cable by truss element, the action such as constant action, vehicle load, the crowd load, temperature load, wind load and so on are considered and simulated.

Considering several commonly used methods of the reasonable finished state determination, combining with span arrangement and structure layout features of cable-stayed bridge with hybrid girder, The reasonable finished state of the bridge is determined by combining the minimum bending energy method and influence matrix method the two kind methods, viewing the maximum displacement of the main pylon and girder as the goal, taking into account the internal force and stress values of the main pylon, main girder, cable.

On the basis of the reasonable finished state determination, the stress values and vertical displacement of cables, girder and pylon on finished state are calculated. On operation state, considering other actions, the cable stress and the girder and the main pylon stress envelope diagram are obtained to checkout stress according to allowed stress of the material used in the bridge structure. Through the check, the stress of each material accord with the requirements of standard, the reasonable finished state of the bridge accord with the requirements.

\section{References}

[1] J.Brozzetti, Design development of steel-concrete composite bridges in France, Journal of Constructional Steel Research. 55(2000) 229-243.

[2] N. Gattesco, Analytical modeling of nonlinear behavior of composite beams with deformable connection, Journal of Constructional Steel Research. 52(1999) 195-218.

[3] A. Heidarpour, T.H. Pham, M.A. Bradford, Nonlinear thermoelastic analysis of composite steel-concrete arches including partial interaction and elevated temperature loading, Engineering Structures. 32(2010) 3248-3257.

[4] Y. Okamoto, S. Nakamura, Static and seismic studies on steel-concrete hybrid towers for multi-span cable-stayed bridges, Journal of Constructional Steel Research. 58(2010) 203-210.

[5] Nobuhito OKUBO, Akimitsu KURITA, Keiichi KOMATSU, Seika NAKAJIMA. Analytical study on mechanical characteristics of steel-concrete composite girder with grouped stud shear connectors, Kou kouzou rombunshuu. 9(2002) 67-75 